\section{"PRESERVED VEGETABLES AGAIN."}

To the Editor of THE LANCET.

SIR,-When some time ago public attention was forcibly drawn to the occasional injurious effects of preserved "canned" goods, I undertook a lengthy series of chemical and physiological experiments to ascertain the cause of such poisonous action. The results having so far only been communicated to professional chemists (The Analyst, vol. v., No. 57), I hope you will allow me, by way of affirmation of the paragraph in THE L.ANCET of Sept. 24th, to give a short summary of them in the columns of your journal, as I think they may be of interest, and of some degree of importance, to medical readers.

Very frequenily the gastric disturbances traceable to the consumption of preserved articles of food have heen assigned to traces of lead dissolved from the solder with which the tins are closed, or present as impurity in the metal with which the can is lined. Now, although the occasional though very rare presence of lead in such articles cannot be denied, the effects should be attributed to the tin itself. Tin, even perfectly pure, is far more readily attacked by food matters than is commonly supposed; it is to be found in comparatively large amounts in an overwhelming majority of canned goods, irrespective of the nature of the same. Acid fruits, such as peaches or cherries, corrode the tins to an appalling extent; but even meats, nay, condensed milk, dissolve and become contaminated with serious quantities of the metal.

I base my observations upon the examination of the following foods:-Vegetable: French asparagus, American asparagus, peas, tomatoes, peaches (three different brands), pine apple (wo kinds), white and red cherries, and marmalade. Animal: Corned beef (five brands), ox cheek, ox tongue (three kinds), collared head, tripe, oysters, sardines in oll, salmon, salmon cutlets, lobster, shrimps, curried fowl (two kinds), bolled rabbit, boiled mutton, roast chicken, reast turkey, ox cheek soup, gravy soup, sausages, condensed milk (three brands).

With the exception of the sausages, the whole of the samples contained more or less tin, many to such an extent that abundant reactions could be obtained from two or three grammes of the vegetable substances; whilst of the animal foods one of the soups contained thirty-five milligrammes, one of the condensed milks eight milligrammes, and oysters forty-five milligrammes of tin to the pound.

Pure tin is readily attacked even by carbonic acid in solution, all samples of soda-water or of other aerated beverages which I have tested giving distinct tin reactions. Aerated beverages are generally stated to be liable to lead contamination, but seeing that lead does not enter into the composition of any of the pipes or vessels of the machines made by modern manufacturers, I do not doubt but that the black colouration produced by sulphuretted hydrogen in the beverage in question has usually been erroneously attributed to lead, and is in reality due to tin. Tin, in fact, prevents the lead passing into solution; it completely precipitates the metal from lead solutions, an equivalent quantity of tin being taken up.

The question arises, Is tin, when taken into the system, injurious to health or not? Forensic literature does not furnish a positive or satisfactory reply, but the following experiments appear to me completely to settle the point.

A half-grown guinea-pig took with its ordinary food seventy-five willigrammes of pure stannous hydrate in two doses of twenty-five and tifty milligrammes each. Death resulted under symptoms of irritant poisoning. Tin was detected in large amount in the fæces and in the viscera, notably the liver.

Another similar animal took within three days, in six doses, 450 milligrammes of stannic hydrate, without serious effect, tin appearing abundantly in the excrements. Accustomed in a manner to stannic salts, it quickly suc. cumbed to fifty milligrammes of stannous hydrate.

It plainly follows that while stannic compounds are not injurious in the doses given, tin in the stannous condition is a virulent irritant poison.

These experiments lead me most strongly to support your demand for a better method of packing preserved food matters than in tin canisters. Tin invariably dissolves in the stannous condition in such solvents as occur in vegetable or animal substances, and the amount of oxygen in the sealed canisters being very minute, oxidation cannot render the metal comparatively unobjectionable.

I trust that the medical profession will object, unmistakably and strongly, to the administration of tin by grocers and oilmen to young and old alike, and, whilst acknowledging the enormous benefits conferred upon the masses by the introduction of preserved foods, will insist that the present system of packing be speedily abandoned. I am, Sir, yours obediently,

OtTo HehNer, F.I.C., F.C.S.,

Billiter-square, E.C., Sept. 24th, 1881. Public Analyst.

\section{GRATUITOUS MEDICAL SERVICES IN HOSPITALS. \\ To the Editor of THE LANCET.}

SIR, - I would like to enlist your interest in a matter which is very much agitating the minds of medical men here just now-viz., gratuitous medical services in rate-supported hospitals. The corporation of this town has nearly completed a hospital for infectious diseases, and the committee proposed to the council the appointment of a salaried non-resident for the present, as only thirty-four beds are being provided (there is room for sixty-eight), a resident to be got when the beds became filled and one was required. The Mayor has actively opposed the committee, and wants an honorary staff with a resident. The members of the medical profession think the propnsal to have gratuitous attendance very wrong. There will be no paupers in the hospital; it is not a charity; the law provides for a salary. Why, then, should medical men give their services for nothing? There would even be a stronger claim for gratuitous services in workhouses. I doubt even if the public will be gratified by the proposal. Patients will go to the hospital by virtue of the same right by which they use the museum or the public parks; yet they will have to receive medical atten. dance as a charity. Nowhere is the result of unlimited medical charity more pernicious than here; but a proposal is made to establish a new branch of charity in a most uncalled-for way-a way which will be injurious alike to the public and to the profession. I think you will agree with me that the attempt to induce medical men to atcend such a hospital gratuitously is most improper, and think it is time a decided stand be made to check the system of indiscriminate medical charity. For if in our infirmaries we have unfitting cases claiming relief, here we have charity forced on every patient alike, not one of the patients being in a position to claim it, and many of them no doubt well able to pay. I trust you will see your way to raising your voice against this most unwise proposal. Although so many medical men view the proposal as a very imppoper one, still there are to be found medical men who might be induced to take the post. - Faithfully yours,

T. WhITESIDE Hime, M. B, \&c.

Leavy Greane House, Sheffield, Sept. 26th, 1881.

\section{HYDROPHOBIA IN MIDDLESEX.}

\section{To the Editor of THE LANCET.}

Srr, - I was lately called to see a case of hydrophobia at Pinner, and I saw the patient on three days. My object in writing to you is not to refer to the medical aspect of the case, but to the legal one; and to point out some inconsistency in our laws. The late $\mathrm{Mr}$. $\mathrm{C}-$ allowed a pet fox-terrier dog to play with and mumble his ear, when he suddenly snapped it. As the poison of hydrophobia, like that of small-pox and some other diseases, can only be derived from a former case, I was anxious to know where the dog became poisoned. I therefore consulted with the verterinary surgeon who attended the dog, and he said: "The dog certainly died mad in about a week; also the other two dogs in the house. I do not know how the dog got rabies, but I am not at all surprised at it, because for the last five or six years they had never been free from mad dogs in the neighbourhood. Two days since I heard the peculiar cry of a mad dog, and was pleased to hear the report of a gun soon afterwards."

It thus appears that the laws permit experiments with the poison of hydrophobia to be made on men and animals for five or six years in a village within a few miles of London. And yet the law is so inconsistent that if I were to perform experiments on a dog, or on a frog, with the view 
to find a cure for the disease, or to discover a vital law which might remove or prevent pain in animals as long as the world lasts, I should be branded as a cruel and immoral wreteh, not by well-informed people, but by a small elique of feminine minds who are ignorant of the laws of living things, and who wish to continue in their ignorance ; and besides, I should subject myself to the operation of penal laws. Such a state of our laws is, in my opinion, a disgrace to the boasted intelligence of the nineteenth century.

\section{I remain, Sir, yours truly,}

ALFRED T'HOS. BRETT, M.D., \&c.

Watford House, Herts, Aug. 29th, 1881.

P.S.-I was so impressed with the defective state of our laws, that in my auniversary presidential address in 1879 to the Hertfordshire Natural History Society I went somewhat out of my way to express my views on the subject, and as they are pertinent to my present letter, perhaps you will allow me to quote them :- "I should like to make a passing remark on what I consider some retrograde and ignorant legislation. I allude to the Act to amend the Act for Prevention of Cruelty to Animals, commonly called the AntiVivisection Act. This is often considered to be a doctor's question, but it concerns the public more than it does the medical profession. I can speak with impartiality because, although I have been a student of medicine for thirty-four years, I have never performed vivisection (except on the human subject), and I do not recollect seeing it done. Yet I can quite understand that to those who wish to extend the boundaries of knowledge it is an important means of research, and such students of nature should have every encouragement and help given them. For a knowledge of the laws of life is necessary for the treatment of disease, and if the public wish to keep the seience of physiology imperfect, and succeed in their object, the treatment of disease will be more imperfect, mure painful, more prolonged, and more expensive than it need be. As to cruelty, I do not believe it. Nothing is so cruel as ignorance, and those who wish to hug their ignorance of biology are the truly cruel. If the public knew their own interest, instead of listening to the blatant cry of a few amiable, but misguided sentimentalists, they would establish physiological laboratories in every large town in the kingdom. There are very few sciences that would be likely to yield such grand results as physiology, and to pay, not only in a pecuniary point of view, but in relieving human suffering as well as that of the animal kingdom for all future ages."-Transactions of the Watford Natural History Society, vol. $i i ., p .10 \%$.

\section{THE PORTABILITY OF DRUGS IN FIELD SERVICE.}

To the Editor of THE LANCET.

SIR,-During the recent campaign in Afghanistan, I was struck with the importance of diminishing as far as possible the bulk of drugs for use in the field. I would urge the attention of wholesale chemists and others to the advantage which would result from compressing quinine, ipecacuanha, and other drugs. Quinine can be compressed into onefourth its bulk, and even less by using higher pressure. Tablets of quinine would be a very easy way of preparing it, and they could be carried in boxes, and not in bottles. Every bottle carried in the field is but a new risk of the loss of its contents. I would like to see them reduced to a minimum, and all possible medicines packed dry in squares, like chocolate, for transport. We should copy the army, and have "medicine cartridges" as far as possible. Thus quinine pills could be sent out to the base of operations, or even made up there in cartridges of 100 or 1000 each, in tinfoil and cardboard or tin boxes. Astringent pills of acetate of lead and opium, a well-known formula, could be and should be prepared in 100 or 1000 cartridges, so that one could telegraph "Send me 5000 astringent pills, No. 12 formula, by field-post." Dover's powder, opium, calomel, tartar emetic, and a number of essential drugs all lend themselves to this cartridge treatment. On the side of an Afghanistan mountain a requisition is sent in to a fieldhospital for drugs. The drugs I may have in plenty, but bottles for them are the difficulty. The medical stores in India issue quinine in $1 \mathrm{lb}$. units in bottles; but smaller quantities, 2 oz. units compressed and packed in tinfoil and cardboard boxes, or compressed to one-fourth in tin boxes as large as an ordinary match-box, would be very convenient, and easily lend themselves to separation.

I take it that a formulary of prescriptions for our army hospitals is absolutely essential. It need not be too elabo. rate, but should contain a very full list of pills and powders. These two modes of administering drugs will be always im. portant in the field; and by having such formularies one could telegraph for the drug wanted, and get it by field-post, and not by the slower transport train. We want above all things to reduce compounding in the field. We want that work done as far as possible at the base. The carriage of chloroform will always necessitate bottles, unless some means can be found to invent a more portable anæsthetic. Chemists might well turn their attention to such a subject.

Water and rum are always with an army, and the dry component elements of mixtures should be issued in hoxes ready for water to be added to produce a large bottle of the mixture needed. Rum can be used to make tinctures of certain drugs in the field. It always forms part of our com. missariat supplies. Concentrated tinctures, needing only extra rum added, would also be of use in the field.

As regards the issuing of a definite formulary for use in army hospitals in the field or in quarters, we must remember that the system of iseuing cartridges to infantry and artillery in the army is merely an attempt to simplify the supply of ammunition to the fighting men. Artillery ofticers, were they allowed, would be striving to modify the weight of the powder and the class of powder used. But necessity has forced the authorities to fix the weight and character of the powder used, and has left the experi. mental part to be done in times of peace. In like manner, we need a definite formula for war service in all the com. moner prescriptions.

Thus it would be better to fix a formula for an astringent pill than run the risk of having no compounder on the spot to combine the opium and the lead. The sickness or death of a compounder in the field is a great loss, but we exaggerate the loss by not minimising the work needed of him. Again, in the field, medical officers and the medical staff are con. centrated from scattered peace hospitals. I order a sick soldier a diaphoretic mixture, and $I$ find the compounder does not use the mixture I have been accustomed to order. It is unfair to ask him to make up a separate mixture for every medical officer in a large hospital. We should agree on a fixed formula, and add any special drugs to that formula if so needed. The experience of officers gained in field service should be put on record for others. I know of no book which an army doctor can read to learn hints to make field service responsibility less onerous than it now is on the medical officers. There is certainly room for a paper on such an important subject.

The supply of drugs in the field, and particularly in the wars we fight in, in wild and uncivilised countries, where transport is so important an item, will always be an interesting subject. I think something might be gained by following the lines I have endeavoured to sketch out.

I remain, Sir, yours truly, G. J. H. EVATT, A.M.D.

Royal Military Academy, Woolwich, Sept. 1881. Surgeon-Miajor.

\section{DUGAS' PATHOGNOMONIC SIGN OF DISLO- CATION OF THE HUMERUS.}

\section{To the Editor of The LANCET.}

SIR,-Having had a case of dislocation (subcoracoid) of the humerus under my care a short time since, in which the above sign proved of great service, I wish to draw the attention of your readers to its value.

The patient was a strong, stout, healthy man, weighing $237 \mathrm{lb}$, and came by his injury through a violent fall sideways upon the inside of his right elbow. The shock was severe, but reaction soon occurred, and it was found impossible to reduce the dislocation in the nsual way. There was some question as to the exact nature of the injury, for a feeling like that of crepitus could be obtained on examination, due either to effusion into or about the joint, or to relaxation and displacement of the tendon of the long head of the biceps muscle. This being the case, and there being also very little deformity and no increased mobility, the depression under the acromion corresponding with the glenoid cavity, and the presence of the head of the bone beneath the coracoid not being pronounced, on account of 